\title{
Hydroxyapatite-based sorbents: elaboration, characterization and application for the removal of catechol from the aqueous phase
}

\author{
Haroun Sebei, Doan Pham Minh, Nathalie Lyczko, Patrick Sharrock and Ange Nzihou \\ Université de Toulouse, Mines Albi, CNRS, Centre RAPSODEE, Albi Cedex 09, France
}

\begin{abstract}
Hydroxyapatite (HAP) is highly considered as good sorbent for the removal of metals from the aqueous phase. However, soluble metals co-exist with organic pollutants in wastewaters. But little work has been devoted to investigate the reactivity of HAP for the removal of organic compounds. The main objective of this work is to study the reactivity of HAP-based sorbents for the removal of catechol as a model organic pollutant from an aqueous solution. Thus, HAP sorbents were firstly synthesized using calcium carbonate and potassium dihydrogen phosphate under moderate conditions $\left(25-80^{\circ} \mathrm{C}\right.$, atmospheric pressure). A zinc-doped HAP was also used as sorbent, which was obtained from the contact of HAP with an aqueous solution of zinc nitrate. All the sorbents were characterized by different standard physico-chemical techniques. The sorption of catechol was carried out in a batch reactor under stirring at room temperature and pressure. Zinc-doped HAP sorbent was found to be more reactive than non-doped HAP sorbents for the fixation of catechol. The highest sorption capacity was of $15 \mathrm{mg}$ of $C$ per gram of zincdoped HAP sorbent. The results obtained suggest the reaction scheme of HAP sorbents with metals and organic pollutants when HAP sorbents were used for the treatment of complex wastewaters.
\end{abstract}

\author{
KEYWORDS \\ Hydroxyapatite; catechol; \\ sorption; wastewater \\ treatment; mechanism
}

\section{Introduction}

The sector of wastewater treatment continues to evolve with new challenges and targets. Nowadays, different configurations exist concerning the treatment of various wastewaters. For urbanized zones, domestic wastewater is usually canalized and commonly treated by a wastewater treatment plant (WWTP) using conventional biological treatment. For a given industrial zone, wastewater from various industrial activities is usually collected and (pre)treated by specific processes. In the case of a mixed zone wherein industrial activities coexist or are in the proximity of an urbanized zone, conventional WWTP receives both domestic and industrial wastewater. In this case, the pretreatment of non-biodegradable organic compounds and toxic heavy metals is crucial for biological digestion. As an example, the WWTP of Graulhet city (Tarn Department, France) receives domestic wastewater as well as wastewater from various industries, particularly from tanneries of the related region. The removal of heavy metal allows accelerating the biological treatment yield. The aeration time is reduced leading to operational energy saving, taking into account the fact that aeration corresponds to about $50 \%$ of the operational cost of a given WWTP.
Heavy metal removal can be done by various techniques: precipitation, adsorption, complexation and cationic exchange [1,2]. For the adsorption process, numerous research works have been devoted to the investigation of calcium hydroxyapatite-based sorbents (HAP). HAP, with the general chemical formula $\mathrm{Ca}_{10}\left(\mathrm{PO}_{4}\right)_{6}(\mathrm{OH})_{2}$, has an exceptional capacity for the fixation of different heavy metals such as $\mathrm{Pb}^{2+}, \mathrm{Zn}^{2+}, \mathrm{Cd}^{2+}$, $\mathrm{Ni}^{2+}, \mathrm{Cu}^{2+}$, etc. [3-6]. Our previous work showed that the sorption capacity of HAP-based sorbents for $\mathrm{Pb}^{2+}$ fixation could reach up to $1226 \mathrm{mg} \mathrm{g}^{-1}$, which is much higher than the sorption capacity of conventional activated carbon [7]. Similar results were obtained for $\mathrm{Zn}^{2+}$ fixation [8]. The results obtained from our research group allowed the first industrial scale-up by our industrial partner, for the treatment of specific wastewaters containing high concentration of heavy metal (nickel and chromium).

If the fixation of heavy metals by HAP-based sorbents is highly studied, the removal of organic pollutants using HAP-based materials is relatively recent. Till date, most of studies focused on the fixation of phenol as the model organic pollutant compound [9-12]. But we can find some works reported on the removal of other organic 
molecules such as light carboxylic acids, amino-acids and dyes [13-16]. Thus, the removal of phenol by synthetic and natural HAP has been investigated. The initial concentration of phenol had an important effect by providing a driving force, enough for surpassing the limit of mass transfer of phenol from the liquid medium to sorbent surface $[9,12]$. For the phenol concentration ranging from 2 to $400 \mathrm{mg} \mathrm{L}^{-1}$, the sorption capacity reached around 4-10 $\mathrm{mg} \mathrm{g}^{-1}$ [10-12]. Specific surface area (by BET method, $S_{\mathrm{BET}}$ ) of HAP-based sorbent was reported as a crucial factor for the sorption capacity of phenol removal. Bahdod et al. [10] investigated the reactivity of three natural HAP-based sorbents having $S_{\mathrm{BET}}$ of 35,55 and $235 \mathrm{~m}^{2} \mathrm{~g}^{-1}$. The increase of $S_{\mathrm{BET}}$ led to the increase of the sorption capacity from 4 to $8 \mathrm{mg} \mathrm{g}^{-1}$. However, this was not linear, which was later explained by the fact that the microporosity of HAP of high $S_{B E T}$ did not allow the penetration of phenol molecules. However, this microporosity was not further detailed [10]. The effect of $\mathrm{pH}$ on the sorption of phenol was also investigated in a large range of $2-12[9,11,12]$. The results obtained were different from each other. Lin et al. [12] showed that the $\mathrm{pH}$ of the solution after sorption experiment was close to that before sorption experiment, and did not depend on the initial $\mathrm{pH}$. They found that the sorption capacity decreased from 2 to 8.2 then increased above 8.2. The maximum sorption capacity was obtained at the $\mathrm{pH}$ of 2 . Similar results were observed by Bouyarmane et al. [11] On the other hand, Alzaydien and Manasreh [9] found the maximum performance at the $\mathrm{pH}$ of 8 . They explained the decrease of the sorption capacity at high $\mathrm{pH}(>9.9)$ by electrostatic repulsions between negative charges of sorbent particles and phenolate groups. At $\mathrm{pH}$ lower than 8 , wherein the phenol was not dissociated, the authors attributed the phenol fixation by 'dispersive interactions'.

Another aromatic model compound investigated was catechol (or 1,2-dihydroxybenzene, $\mathrm{C}_{6} \mathrm{H}_{4}(\mathrm{OH})_{2}$ ). Chirdon et al. [17] studied the adhesion of catechol and other organic compounds on the surface of a synthetic HAP. The adhesion work of these organic compounds on the HAP surface was thus determined. With two adjacent hydroxyl groups, catechol had the highest adhesion energy, around $90 \mathrm{~mJ} \mathrm{~m}^{-2}$. Molecules containing alcohol, amine and carboxyl groups had lower adhesion energy (around $60-70 \mathrm{~mJ} \mathrm{~m}^{-2}$ ). The sorption capacity of HAP sorbent for catechol was also determined by adsorption isotherm, and reached $35 \mu \mathrm{mmol} \mathrm{g}{ }^{-1}$. This last was higher than that obtained with the alcohol, amine and carboxyl compounds investigated [17].

About the sorption of light carboxylic acids using HAP-based sorbents, Wei et al. [15] investigated the reactivity of both amorphous and crystalline HAP for the removal of oxalic acid $(\mathrm{HOOC}-\mathrm{COOH})$, citric acid $\left(\left(\mathrm{HOOC}-\mathrm{CH}_{2}\right)_{2} \mathrm{C}(\mathrm{OH})(\mathrm{COOH})\right)$ and malic acid ( $\mathrm{HOOC}-$ $\left.\mathrm{CH}_{2}-\mathrm{CH}(\mathrm{OH})(\mathrm{COOH})\right)$. The fixation of oxalic acid $\left(0.5 \mathrm{mmol} \mathrm{g}^{-1}\right)$ was more important than that of citric and malic acids $\left(<0.2 \mathrm{mmol} \mathrm{g}^{-1}\right)$. This was explained by high polarity of oxalic acid which favors the fixation of this acid by the polar surface of HAP sorbents. In addition, oxalate ions could form an insoluble complex with calcium cation $\left(\mathrm{Ca}^{2+}\right)$ generated from the acid attack on HAP surface particles. This favors also the fixation of oxalic acid compared to two others. Bengtsson [13] studied the interaction of malonic acid ( $\mathrm{HOOC}-$ $\left.\mathrm{CH}_{2}-\mathrm{COOH}\right)$, citric acid and mellitic acid $\left(\mathrm{C}_{6}-(\mathrm{COOH})_{6}\right)$ with synthetic HAP sorbents. They attributed the fixation of these acids by the formation of outer sphere complex at the water-HAP particle interfaces as well as the cooperative electrostatic interactions. Thus, the sorption was favored at $\mathrm{pH}$ lower than 8 . Above $\mathrm{pH}$ of 8 , the retention of these acids strongly decreased [13]. Vega and Colinas [14] investigated the removal of isomeric fumaric and maleic acids ( $\left.\mathrm{HOOC}-\mathrm{CH}_{2}=\mathrm{CH}_{2}-\mathrm{COOH}\right)$ using a synthetic HAP. They demonstrated that these acids were practically fixed on the surface of HAP particles in carboxylate form. The highest performances were observed at $\mathrm{pH}$ of 4.1 for fumaric acid ( $\mathrm{pK}_{\mathrm{a}}$ of 3 and 4.2) and 5.2 for maleic acid ( $\mathrm{pK}_{\mathrm{a}}$ of 1.8 and 6.1) [14]. We note that these light carboxylic acids are generally biodegradable and can be digested by the conventional biological process. On the other hand, (poly)phenolic compounds such as phenol and catechol are more bio-recalcitrant and usually need a pretreatment before the biological digestion [18].

The reactivity of a synthetic HAP for the simultaneous removal of metals and organic compounds from a real wastewater withdrawn from the WWTP of Graulhet city (France) was recently reported by our research team [19]. Using a semi-continuous pilot reactor wherein the real wastewater continuously passed through a batch of HAP sorbent, the experiment was kept for a long reaction time of 30 days. The sorption performance was monitored for various elements ( $\mathrm{Pb}, \mathrm{Ni}, \mathrm{Sb}, \mathrm{Se}, \mathrm{Zn}, \mathrm{As}, \mathrm{Cd}, \mathrm{Co}$, $\mathrm{Cr}, \mathrm{Cu}, \mathrm{Mn}, \mathrm{Fe}, \mathrm{Mo}, \mathrm{Al}$ ) and for the total organic carbon (TOC) value during the experiment. For the fixation of metals, the performance reached above $60 \%$ for most of the investigated metals. High performance of TOC fixation was also observed with the weight loss up to $35 \%$ obtained by TG-DSC analysis of the sorbent recovered after 30 days of use. This result demonstrated that HAP removed simultaneously metals and organic pollutants from the aqueous phase. This is particularly interesting for the case of the WWTP which receive both domestic and industrial wastewaters. HAP allows reducing most of the metals present in this mixed wastewater, thus 
favoring the ulterior biological treatment step. However, as presented above, there is little work that investigates the fixation of organic pollutants by HAP-based sorbents, in particular phenolic compounds other than phenol. And the results obtained were sometimes contradictory. So this task merits further investigations.

This work aimed to study the removal of catechol (1,2dihydroxybenzene, $\mathrm{C}_{6} \mathrm{H}_{4}(\mathrm{OH})_{2}$ ) from an aqueous solution by different synthetic HAP-based sorbents. The main objective was to investigate the interaction of HAP-based matrix with a phenolic model compound. The results of this work will contribute to the understanding of the performance of the synthesized HAP-based sorbents for the treatment of a real effluent, as mentioned above [19].

\section{Experimental}

\subsection{Synthesis of HAP-based sorbents}

Calcium carbonate powder $\left(\mathrm{CaCO}_{3}, 98 \%\right.$, Fisher Scientific) and potassium dihydrogen orthophosphate $\left(\mathrm{KH}_{2} \mathrm{PO}_{4}\right.$, 99\%, Fisher Scientific) were used for the synthesis of HAP sorbents. The synthesis was carried out in a $1 \mathrm{~L}$ glass reactor thermostated at $25^{\circ} \mathrm{C}$ or $80^{\circ} \mathrm{C}$ during the synthesis. Firstly, an aqueous solution of $\mathrm{KH}_{2} \mathrm{PO}_{4}\left(1.2 \mathrm{~mol} \mathrm{~L}^{-1}\right)$ was prepared. Then, calcite powder was progressively added into the solution of $\mathrm{KH}_{2} \mathrm{PO}_{4}$. The final theoretical molar ratio of $\mathrm{Ca}$ to $\mathrm{P}$ was 1.67 , which is characteristic for stoichiometric HAP. The mixture was stirred for $48 \mathrm{~h}$ with the rotation rate of $350 \mathrm{rpm}$ with a helical propeller. After $48 \mathrm{~h}$, the suspension was filtered on a $0.45-\mu \mathrm{m}$ hydrophilic filter to separate liquid and solid phases. The solid was washed several times with permuted water, dried overnight at $105^{\circ} \mathrm{C}$ before further analyses and utilization. The liquid phase was acidified with nitric acid to avoid all secondary precipitation from calcium cations and orthophosphate species present in the liquid phase. The solids obtained at $25^{\circ} \mathrm{C}$ and $80^{\circ} \mathrm{C}$ were thereafter called HAP_25 and HAP_ 80 which were then used as sorbents for the removal of catechol.

Another sorbent used for the removal of catechol was derived from HAP_25 after its utilization for $\mathrm{Zn}^{2+}$ removal. Our previous study was done on the fixation of $\mathrm{Zn}^{2+}$ (initial concentration of $1500 \mathrm{mg} \mathrm{L}^{-1}$ ) by HAP_25 [8]. We have recovered this solid, called hereafter HAP_25_Zn, for use in the removal of catechol. The composition of three sorbents used in this work is given in Table 1.

\subsection{Sorbents' characterization and analysis}

The $\mathrm{pH}$ of zero charge point $\left(\mathrm{pH}_{\mathrm{ZCP}}\right)$ was experimentally determined according to the previous description
Table 1. Chemical composition of the sorbents used in this work.

\begin{tabular}{lcccc}
\hline Sorbent & $\mathrm{Ca}, \mathrm{mmol} \mathrm{g}^{-1}$ & $\mathrm{P}, \mathrm{mmol} \mathrm{g}^{-1}$ & $\mathrm{Ca} / \mathrm{P}$ & $\mathrm{Zn}, \mathrm{mg} \mathrm{g}^{-1}$ \\
\hline HAP_25 & 8.9 & 3.7 & 2.38 & 0 \\
HAP_80 & 9.4 & 4.6 & 2.05 & 0 \\
HAP_25_Zn & 7.1 & 3.8 & 1.88 & 118 \\
\hline
\end{tabular}

$[20,21]$. Elemental analysis was done with the inductive coupled plasma atomic emission spectroscopy (ICPAES, HORIBA Jobin Yvon Ultima 2 apparatus).

The specific surface area was determined using the BET method $\left(S_{\text {BET }}\right)$ with a MICROMERITICS ASAP 2010 apparatus. The true density was obtained from a helium pycnometry (MICROMERITICS Accupyc 1330). Thermogravimetric analysis coupled with differential scanning calorimetry (TG-DSC) was performed with an SDT Q600 (TA instruments). For each analysis, around $30 \mathrm{mg}$ of sample was used under $\mathrm{N}_{2}$ flow rate of

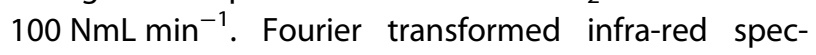
troscopy (FTIR) was carried out with a SHIMADZU $8400 \mathrm{~S}$ spectrophotometer scanning between 4000 and $500 \mathrm{~cm}^{-1}$. The particle size distribution of the sorbents was determined with a MALVERN Laser Mastersizer Hydro 2000 in liquid medium. X-ray diffraction (XRD) was conducted using a Philips X'Pert diffractometer with copper anti-cathode. The identification of crystalline phases was carried out by comparing the XRD patterns with JCPDS standards.

\subsection{Sorption experiments}

The removal of catechol was carried out in a 350-mL glass batch reactor at room temperature and atmospheric pressure. For each experiment, $300 \mathrm{~mL}$ of an aqueous solution of catechol were added to the reactor under stirring $(300 \mathrm{rpm})$. The initial concentration of catechol was fixed in the range of 100$1000 \mathrm{mg} \mathrm{L}^{-1}$, which corresponds to the TOC concentration of $65-653 \mathrm{mg} \mathrm{L}^{-1}$. The sorption was started by adding a weighed amount of a sorbent into the reactor. All the experiments were carried out under room temperature and atmospheric pressure. The reaction time was fixed for $2 \mathrm{~h}$. This duration was chosen to limit the effect of the auto-oxidation of catechol by dissolved oxygen in water. After $2 \mathrm{~h}$ of reaction, the concentration of catechol was determined by high performance liquid chromatography (HPLC, Dionex system, PRP-X 300 column of $250 \times$ $4.1 \mathrm{~mm}$, UV detector). TOC measurements were carried out with a Shimadzu 5050 TOC analyzer. It allows analyzing the TOC of both the liquid and the solid phases. The conversion of catechol and liquid TOC was calculated according to the following 
equations:

$$
\begin{aligned}
& \text { Catechol conversion }(\%)=\frac{C_{\text {catechol }}^{\text {initial }}-C_{\text {catechol }}^{\text {final }}}{C_{\text {catechol }}^{\text {initial }}} \times 100, \\
& \text { Liquid TOC conversion }(\%)=\frac{\mathrm{TOC}_{\text {liquid }}^{\text {initial }}-\mathrm{TOC}_{\text {liquid }}^{\text {final }}}{\mathrm{TOC}_{\text {liquid }}^{\text {initial }}} \times 100 .
\end{aligned}
$$

\section{Results and discussion}

\subsection{Characterization of the fresh sorbents}

\subsubsection{Composition by ICP-AES}

Firstly, the composition of all the sorbents was determined by ICP-AES (Table 1). For the sorbent synthesized at $25^{\circ} \mathrm{C}$, the conversion of $\mathrm{CaCO}_{3}$ and $\mathrm{KH}_{2} \mathrm{PO}_{4}$ into apatitic calcium phosphate reached $70 \%$ [8]. The bulk molar ratio of $\mathrm{Ca}$ to $\mathrm{P}$ of this sorbent was 2.38. At the synthesis temperature of $80^{\circ} \mathrm{C}$, the conversion of $\mathrm{CaCO}_{3}$ and $\mathrm{KH}_{2} \mathrm{PO}_{4}$ reached $95 \%$. The bulk molar ratio of $\mathrm{Ca}$ to $\mathrm{P}$ of this sorbent was 2.05. For the zinc-containing sorbent, the molar ratio of $\mathrm{Ca}$ to $\mathrm{P}$ decreased to 1.88 because of the partial replacement of $\mathrm{Ca}^{2+}$ by $\mathrm{Zn}^{2+}$ during the fixation of $\mathrm{Zn}^{2+}$ [8]. Some trace amounts of potassium was still observed in all the sorbents.

\subsubsection{XRD characterization}

Figure 1 shows the XRD patterns of the initial sorbents used in this work. For the sorbent synthesized at $25^{\circ} \mathrm{C}$ (HAP_25), different crystalline phases were observed, including the residual calcite (JCPDS standard $\mathrm{N}^{\circ}$ 01-072-1937), HAP (JCPDS standard $\mathrm{N}^{\circ}$ 00-001-1008) with the main peak at $32^{\circ}$, octacalcium bis(hydrogenphosphate) tetrakis(phosphate) pentahydrate (OCP, $\mathrm{Ca}_{8}\left(\mathrm{HPO}_{4}\right)_{2}\left(\mathrm{PO}_{4}\right)_{4} \cdot 5 \mathrm{H}_{2} \mathrm{O}$, JCPDS standard $\mathrm{N}^{\circ}$ 01-047-0260) and carbonated hydroxyapatites (CAP). The presence of OCP was further confirmed by its

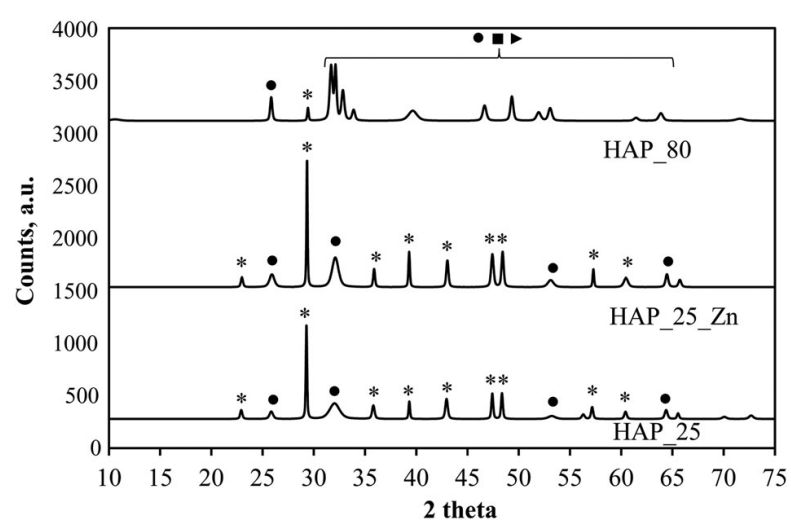

Figure 1. XRD patterns of the initial sorbents used in this work; $\left.{ }^{*}\right)$ calcite; (O) HAP; (ø) OCP; $(\bullet)$ CAP. main peak at $4.7^{\circ}$. The presence of CAP was thereafter confirmed by TG-DSC analysis thereafter.

For the zinc-doped sorbent (HAP_25_Zn), calcite was always present in this sorbent (JCPDS standard $\mathrm{N}^{\circ} 01$ 072-1937). The presence of CAP or HAP was still confirmed with the main peak at $32^{\circ}$. On the other hand, OCP disappeared, which suggests the participation of this compound to the fixation of $\mathrm{Zn}^{2+}$ [8]. Despite the high content of $\mathrm{Zn}$ in this sorbent (11.8 wt.\%), as shown by ICP-AES analysis (Table 1), any crystalline phase of zinc was observed for this sorbent. Did zinc exist under amorphous forms? Further analysis is needed to identify the chemical structure of zinc-containing compounds.

For the sorbent obtained at $80^{\circ} \mathrm{C}$ (HAP_80), different apatitic calcium phosphates were present: HAP, CAP, OCP. Compared to the sorbent synthesized at $25^{\circ} \mathrm{C}$, HAP_80 had a higher crystallinity with fine XRD peaks and good resolutions. Finally, crystalline calcite was still present, because the synthesis reaction of $\mathrm{CaCO}_{3}$ with $\mathrm{KH}_{2} \mathrm{PO}_{4}$ was not finished after $48 \mathrm{~h}(95 \%)$.

\subsubsection{TG-DSC analysis}

TG analysis of the initial sorbent is presented in Figure 2. DTG signals allowed highlighting the thermal behavior of the sorbents. The weight losses below $600^{\circ} \mathrm{C}$ could be attributed to the dehydration of surface water, brushite $\left(\mathrm{CaHPO}_{4} \cdot 2 \mathrm{H}_{2} \mathrm{O}\right)$, monetite $\left(\mathrm{CaHPO}_{4}\right)$ or hopeite $\left(\mathrm{Zn}_{3}\left(\mathrm{PO}_{4}\right)_{2} \cdot 4 \mathrm{H}_{2} \mathrm{O}\right)[22,23]$. The presence of brushite as intermediate of the HAP synthesis was already confirmed by XRD. This compound thermally decomposed around $130-200^{\circ} \mathrm{C}$ to form monetite. This compound decomposed near $430^{\circ} \mathrm{C}$ [22]. On the other hand, the hydydration of hopeite is usually complex which depends on its crystallinity as well as its dimorphic $\alpha$ and $\beta$ forms [24]. In general, the dehydration of this compound can take place around $120-190^{\circ} \mathrm{C}$ then $280-370^{\circ} \mathrm{C}$ [24].

All three sorbents had weight losses around 600 and $800^{\circ} \mathrm{C}$. These correspond to the decomposition of the residual calcium carbonate (close to $600^{\circ} \mathrm{C}$ ) and CAP (close to $800^{\circ} \mathrm{C}$ ). The decarbonation of CAP has been previously discussed $[22,25,26]$.

\subsubsection{FTIR analysis}

Figure 3 shows FTIR spectra of the initial sorbents. For HAP_25 and HAP_80, the characteristic bands of apatitic phosphate groups $\left(\mathrm{PO}_{4}^{3-}\right)$ were observed around $1030 \mathrm{~cm}^{-1}$, and at 600 and $560 \mathrm{~cm}^{-1}$ [27]. The large peak around $1030 \mathrm{~cm}^{-1}$ can be explained by the low crystallinity of the sorbents. The large vibration band at $3600-3000 \mathrm{~cm}^{-1}$ was due to molecular water. The very week vibration band at $630 \mathrm{~cm}^{-1}$ could be attributed to hydroxyl groups $\left(\mathrm{OH}^{-}\right)$of the apatitic structure. The peaks at 1400,872 and $712 \mathrm{~cm}^{-1}$ correspond to the 

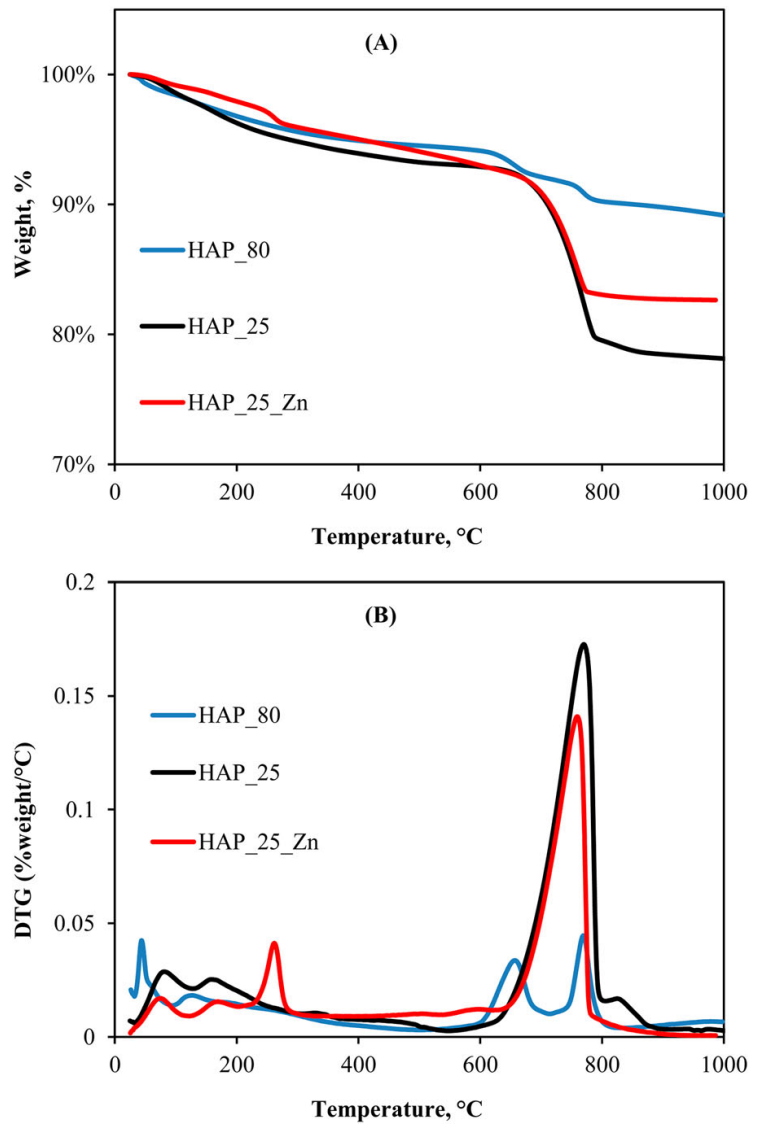

Figure 2. TG-DSC analysis of the initial sorbents used in this work; (a) weight loss, (b) derivative weight loss (DTG).

vibration of carbonate groups $\left(\mathrm{CO}_{3}^{2-}\right)$ from the residual calcite in these sorbents. The presence of CAP in these two sorbents was again confirmed by the vibration bands at $1480,1450,1410,875$ and $858 \mathrm{~cm}^{-1}$ [28,29].

\subsubsection{Particle size distribution}

Figure 4 presents the particle volume distribution of the sorbents as a function of the particle size. In all cases, different particle populations were observed. Fine particles around $1 \mu \mathrm{m}$ were present at low volume

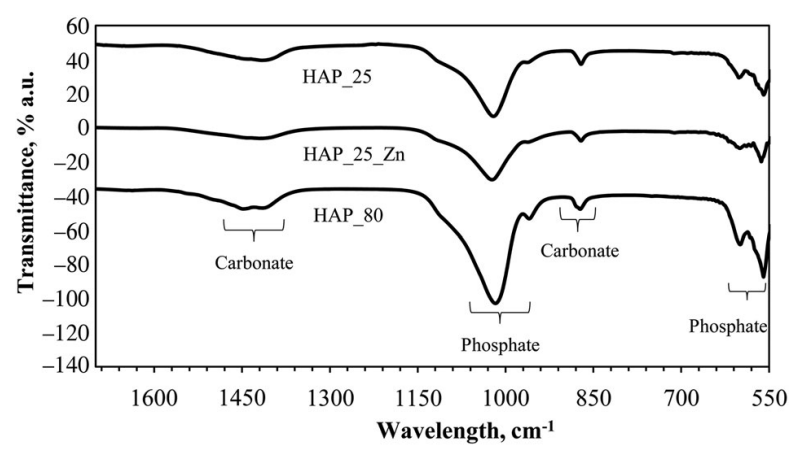

Figure 3. FTIR spectra of the initial sorbents used in this work.

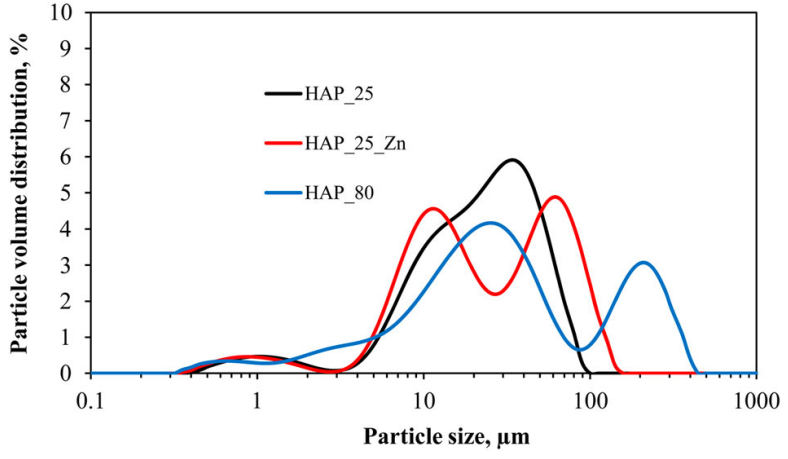

Figure 4. Volume distribution as a function of particle size of the initial sorbents used in this work; particle size in base 10-logarithmic scale.

distribution. The accumulated volume of particles smaller than $2 \mu \mathrm{m}$ did not exceed 5\%. HAP_25 contained the second population which extended from 2 to around $85 \mu \mathrm{m}$. The peak of this second population seemed to be under bimodal mode. Compared to HAP_25, HAP_80 had in addition the third population in the range of 85-450 $\mu \mathrm{m}$. The presence of large calcium phosphate particles in these sorbents might be due to the agglomeration phenomenon, as suggested by SEM analysis (Figure 5). For HAP_25_Zn sorbent, particle volume distribution was similar to that of HAP_25. However, the bimodal mode of the second population was clear and the particle size of this sorbent extended up to around $165 \mu \mathrm{m}$. Table 2 summarizes the value of $d_{90}$ of all the sorbents.

\subsubsection{Specific surface area $\left(S_{B E T}\right)$, true density, point of zero charge $\left(\mathrm{pH} \mathrm{HPC}_{\mathrm{ZPC}}\right.$ ) and solubility product $\left(\mathrm{K}_{\mathrm{s}}\right)$}

Table 2 summarizes different physico-chemical properties of the sorbents used in this work. HAP_25 had

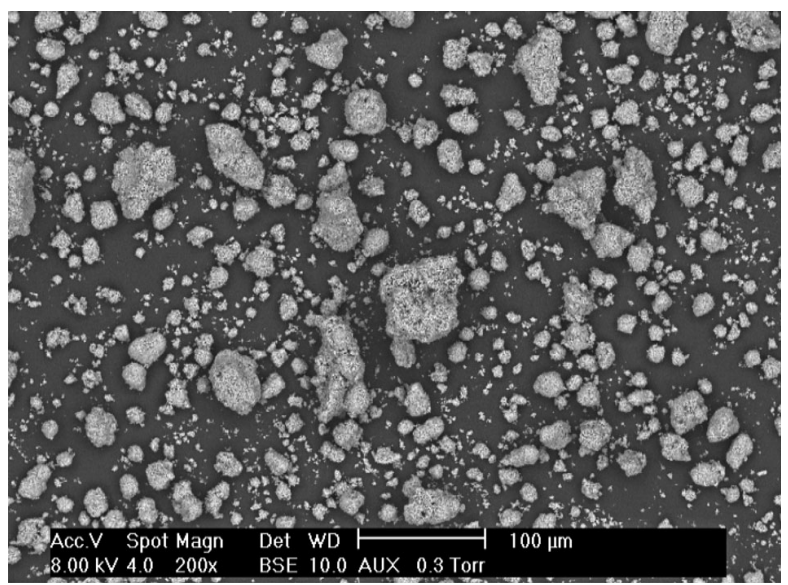

Figure 5. Example of SEM image of HAP_80 sorbent; large particles were formed by agglomeration of small particles. 
Table 2. Physico-chemical properties of the initial sorbents used in this work.

\begin{tabular}{lccccr}
\hline Sorbent & $\begin{array}{c}\mathrm{S}_{\mathrm{BET},} \\
\mathrm{m}^{2} \mathrm{~g}^{-1}\end{array}$ & $\begin{array}{c}\text { True density, } \\
\mathrm{g} \mathrm{cm}^{-1}\end{array}$ & $\mathrm{pH}_{\mathrm{ZPC}}$ & $K_{\mathrm{s}}$ & $\begin{array}{r}d_{90} \\
\mu \mathrm{m}\end{array}$ \\
\hline HAP_25 & 145 & 2.61 & 9.5 & $1.8^{*} 10^{-94}$ & 95 \\
HAP_80 & 66 & 2.79 & 9.5 & $6.8^{*} 10^{-98}$ & 235 \\
HAP_25_Zn & 123 & 2.84 & 8.9 & $5.4^{*} 10^{-99}$ & 85
\end{tabular}

high specific surface area of $145 \mathrm{~m}^{2} \mathrm{~g}^{-1}$, explained by the presence of mesopores in this sorbent [8]. HAP_80 had smaller $S_{\text {BET }}$ compared to HAP_25, which was probably due to the higher synthesis temperature. Consequently, HAP_80 was slightly denser than HAP_25. Both these sorbents had similar $\mathrm{pH}_{\mathrm{ZPC}}$, but HAP_80 was much less soluble in water than HAP_25. This could certainly be due to the higher crystallinity of HAP_80 compared to HAP_25, as evidenced above by XRD characterization. For the HAP_25_Zn sorbent, the fixation of $\mathrm{Zn}^{2+}$ (11.8 wt.\%) led to a decrease of $S_{\mathrm{BET}}, \mathrm{pH}_{\mathrm{ZPC}}$ and $K_{\mathrm{s}}$ as well as a slight increase of the true density compared to the HAP_25 sorbent. The large difference of the solubility product between HAP_25 and HAP_25_Zn explained the high affinity of apatitic sorbent for $\mathrm{Zn}^{2+}$ fixation [8].

\subsection{Results on catechol sorption}

\subsubsection{Evolution of the concentration of catechol and TOC in the aqueous solution}

The first experiments were carried out with an aqueous solution containing $1000 \mathrm{mg} \mathrm{L}^{-1}$ of catechol. Figure 6 presents the fraction of catechol and TOC that remained in the solution after $2 \mathrm{~h}$ of contact with $5 \mathrm{~g} \mathrm{~L}^{-1}$ of sorbent. At this high concentration of catechol (1000 $\mathrm{mg} \mathrm{L}^{-1}$ ), the conversion of catechol reached from $6.2 \%$ to $13.2 \%$ after $2 \mathrm{~h}$ of contact with the sorbents. Catechol could be adsorbed on the surface of the sorbents and/or chemically degraded into intermediates

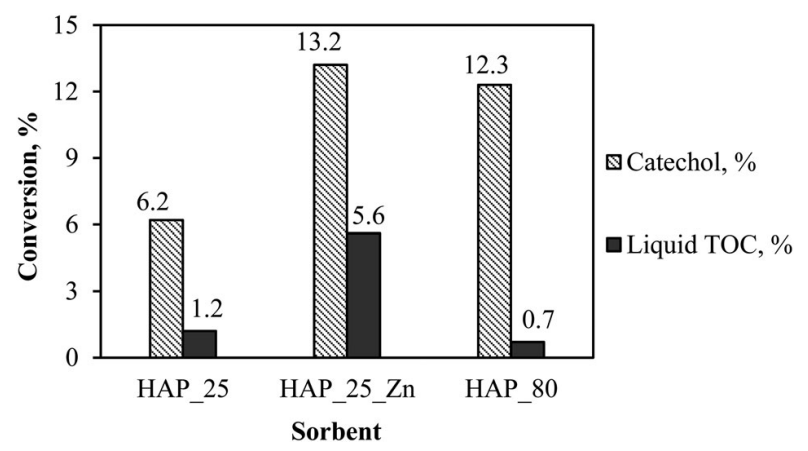

Figure 6. Conversion of catechol and TOC after $2 \mathrm{~h}$ of test: initial concentration of catechol of $1000 \mathrm{mg} \mathrm{L}^{-1}$, sorbent concentration of $5 \mathrm{~g} \mathrm{~L}^{-1}$. by oxidation processes. TOC measurement of the liquid phase showed that in all cases, liquid TOC conversion was smaller than catechol conversion. So, a fraction of catechol was transformed into intermediates which were soluble in the aqueous phase. Both the nondoped sorbents (HAP_80 and HAP_25) showed low conversion of liquid TOC which ranged from 0.7 to $1.2 \%$. The HAP_25_Zn sorbent showed high reactivity with $5.6 \%$ of liquid TOC conversion, which must be probably due to the catalytic property and/or the high affinity of $\mathrm{Zn}$ species for the degradation and fixation of organic compounds.

Figure 7 shows the results obtained with HAP_25 and HAP_25_Zn for the removal of catechol at a low concentration of $100 \mathrm{mg} \mathrm{L}^{-1}$. The decrease of the initial concentration of catechol led to higher liquid TOC and catechol conversions, compared to the results of Figure 6. High conversions of catechol and liquid TOC were observed with HAP_25 and HAP_25_Zn. On the other hand, HAP_80 showed very low reactivity. This will be explained in the next sections.

\subsubsection{Evolution of $\mathrm{pH}$ in the liquid phase during the sorption}

Figure 8 shows the evolution of $\mathrm{pH}$ as a function of contact time during the sorption of catechol. At the concentration range of catechol of $100-1000 \mathrm{mg} \mathrm{L}^{-1}$, the initial $\mathrm{pH}$ was around 5.2-5.3. In all cases, the pH increased quickly above 7.5 within the first minutes of contact with the sorbents. Then, the $\mathrm{pH}$ slowly decreased with the contact time, but remained higher than 7.5 in all cases. This stagnant $\mathrm{pH}$ might be explained by the buffer effect of the presence of residual calcium carbonate and/ or calcium phosphate compounds. For both the concentrations of catechol, the pH order was: HAP_25 > HAP_80 $>$ HAP_25_Zn. A previous study showed that the increase of $\mathrm{pH}$ is favorable for the degradation of catechol [30]. But the most reactive sorbent was HAP_25_Zn, which

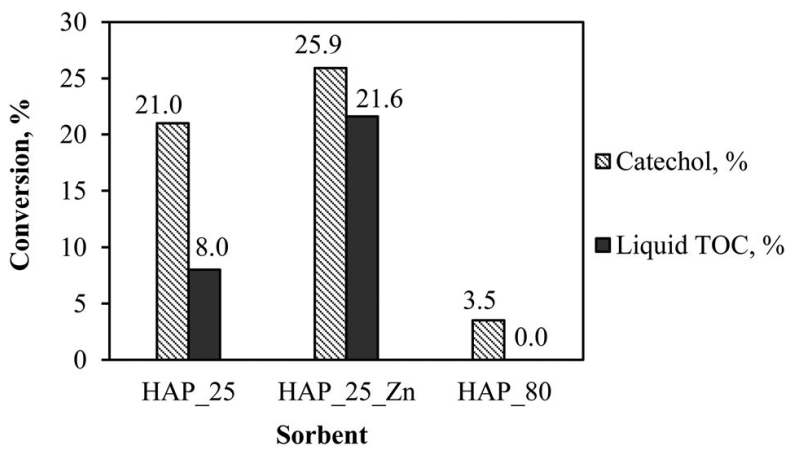

Figure 7. Conversion of catechol and TOC after $2 \mathrm{~h}$ of test: initial concentration of catechol of $100 \mathrm{mg} \mathrm{L}^{-1}$, sorbent concentration of $5 \mathrm{~g} \mathrm{~L}^{-1}$. 

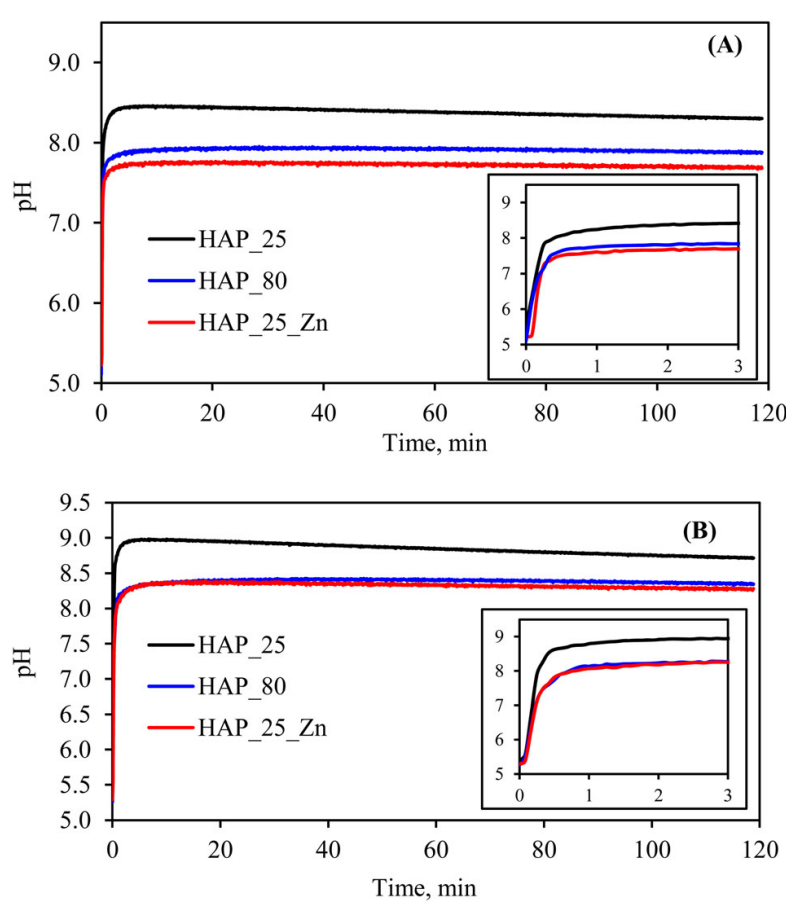

Figure 8. $\mathrm{pH}$ evolution during catechol removal with the initial concentration of catechol of $1000 \mathrm{mg} \mathrm{L}^{-1}$ (a) and $100 \mathrm{mg} \mathrm{L}^{-1}$ (b); inserts $\mathrm{pH}$ within three first min.

led to the lowest $\mathrm{pH}$ in the solution. This must be due to the effect of $\mathrm{Zn}$ on the degradation/fixation of catechol compared to non-doped sorbents.

\subsubsection{Role of soluble metals $\left(\mathrm{Ca}^{2+}, \mathrm{Zn}^{2+}\right)$}

In aqueous solution, calcium phosphates are sensitive to $\mathrm{pH}$ and can be leached during the test. The concentration of soluble zinc and calcium after $2 \mathrm{~h}$ of test was determined and presented in Figure 9. Among the two non-doped sorbents, HAP_25 had a higher solubility than that of HAP_80. In fact, HAP_25 had a lower crystallinity compared to HAP_80 (Figure 1). The higher

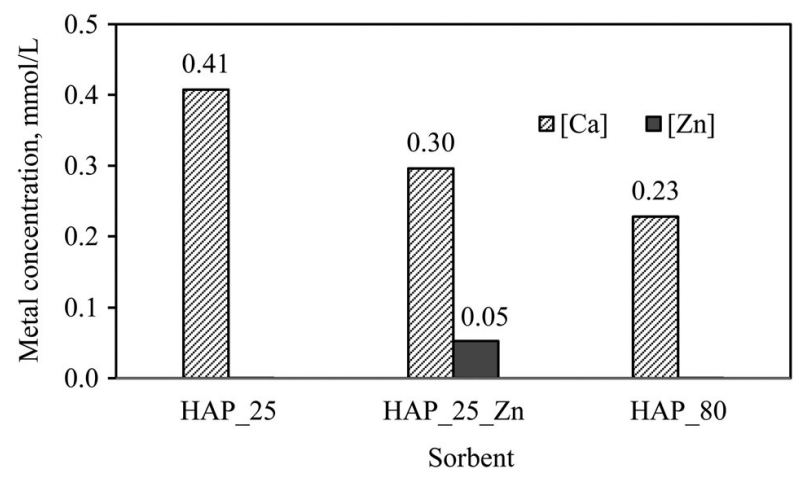

Figure 9. Concentration of soluble zinc and calcium in the aqueous phase after $2 \mathrm{~h}$ of test with the initial concentration of catechol of $100 \mathrm{mg} \mathrm{L}^{-1}$ and sorbent concentration of $5 \mathrm{~g} \mathrm{~L}^{-1}$.
Table 3. Distribution of $\mathrm{Ca}$ and $\mathrm{Zn}$ in liquid and solid phases after $2 \mathrm{~h}$ of test with the initial concentration of catechol of $100 \mathrm{mg} \mathrm{L}^{-1}$ and sorbent concentration of $5 \mathrm{~g} \mathrm{~L}^{-1}$.

\begin{tabular}{lcccccc}
\hline & \multicolumn{2}{c}{ Calcium distribution (\%) } & & \multicolumn{2}{c}{ Zinc distribution (\%) } \\
\cline { 2 - 3 } \cline { 5 - 6 } Sorbent & Liquid form & Solid form nn & & Liquid form & Solid form \\
\hline HAP_25 & 1.0 & 99.0 & & - & - \\
HAP_25_Zn & 0.8 & 99.2 & & 0.9 & 99.1 \\
HAP_80 & 0.6 & 99.4 & & - & - \\
\hline
\end{tabular}

solubility of HAP_25 might be also explained by the presence of intermediates such as brushite, monetite and calcite, which are generally more soluble than apatitic components. For HAP_25_Zn, both soluble calcium and zinc were observed but the concentration of calcium was high than that of zinc. From the results in Figure 9, we could determine the distribution of zinc and calcium in liquid and solid phases at $2 \mathrm{~h}$ of test (Table 3 ).

The results in Figure 9 and Table 3 show that it is necessary to investigate the influence of the soluble metals on the degradation of catechol. Supplementary experiments have been carried out without solid sorbent at constant $\mathrm{pH}$. In order to keep the $\mathrm{pH}$ unchanged, a buffer solution was prepared using tris (hydroxymethyl)aminomethane (TRIS, $\mathrm{C}_{4} \mathrm{H}_{11} \mathrm{NO}_{3}$ ) of $0.2 \mathrm{M}$. The $\mathrm{pH}$ of this solution was adjusted to 8.5 by using $7.8 \mathrm{M} \mathrm{HNO}_{3}$ solution [31]. This buffer solution was then used for preparing $100 \mathrm{mg} \mathrm{L}^{-1}$ catechol solution for sorption tests. These were performed with and without soluble zinc or calcium addition (nitrate salts). The amount of zinc nitrate or calcium nitrate was calculated to get $0.9 \mathrm{mmol} \mathrm{L}^{-1}$ in the final solution of the sorption test. This metal concentration was much higher than the soluble zinc and calcium determined in Figure 9 in order to clarify the effect of soluble metals. Figure 10 presents the results obtained.

Catechol decomposed itself in the aqueous solution. The conversion of $3.37 \%$ was observed after $2 \mathrm{~h}$ of reaction at $\mathrm{pH} 8.5$, without catalyst. The addition of soluble

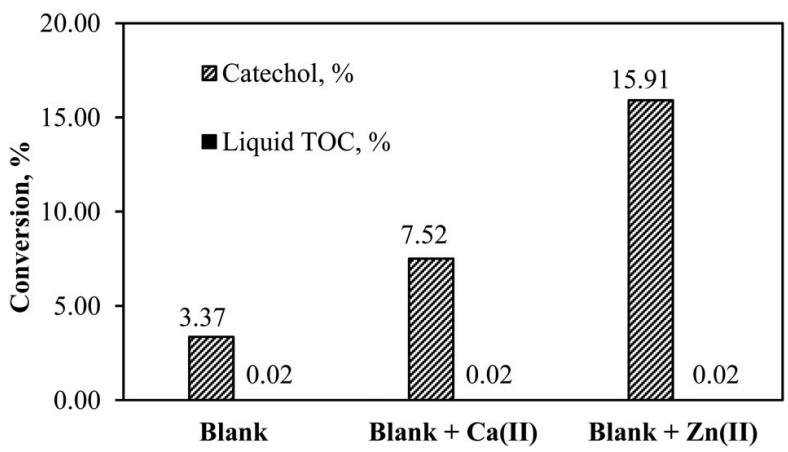

Figure 10. Degradation of catechol with and without soluble metal addition after $2 \mathrm{~h}$ of test: initial concentration of catechol of $100 \mathrm{mg} \mathrm{L}^{-1}$, calcium or zinc concentration of $0.9 \mathrm{mmol} \mathrm{L}^{-1}$. 
calcium or zinc accelerated this decomposition. Zinc was found to be more efficient with $15.9 \%$ of catechol conversion compared to calcium with 7.5 of catechol conversion after $2 \mathrm{~h}$ of contact. The presence of soluble zinc or calcium accelerated only the degradation of catechol, but it did not affect the mineralization. The value of liquid TOC was practically unchanged with or without soluble metal addition (Figure 10). In fact, the mineralization of organic compounds into $\mathrm{CO}_{2}$ and $\mathrm{H}_{2} \mathrm{O}$ in the aqueous phase needs generally high temperature and pressure in the absence or in the presence of a homogeneous metal catalyst [32,33].

The catalytic effect of divalent metallic cations such as $\mathrm{Zn}^{2+}, \mathrm{Ca}^{2+}, \mathrm{Mg}^{2+}, \mathrm{Ba}^{2+}, \mathrm{Sr}^{2+}$ on the decomposition of catechol has been previously demonstration by Lebedev et al. [30] Thus, a metal-catechol complex was formed which favors the dissociation (deprotonation) of hydroxyl groups. This additional deprotonation favors the transfer and the propagation of free radicals in the reaction medium, which are responsible for the initiation degradation of catechol [30]. In another study, Bhatt and Shah also demonstrated the formation of metal-catechol complex for various divalent metals including $\mathrm{Ni}^{2+}, \mathrm{Cu}^{2+}, \mathrm{Zn}^{2+}, \mathrm{Cd}^{2+}, \mathrm{Pb}^{2+}$ [34].

\subsubsection{Carbon balance}

Sorption results in Figures 6 and 7 show that the liquid TOC conversion was not negligible using HAP-based sorbents. This liquid TOC conversion could be attributed to the fixation of organic species on the surface of the sorbent, and/or the mineralization of organic compounds. In order to determinate the nature of the liquid TOC conversion, the solids recovered after sorption tests were analyzed by solid TOC. Table 4 shows the TOC distribution in solid and liquid phases.

In all cases, the carbon balance could be buckled. The sum of TOC in liquid and solid phases was close to the initial quantity of TOC introduced into the reactor. This evidences that any mineralization took place at room temperature and pressure under the presence of HAPbased sorbents. The addition of zinc on the surface of HAP strongly improved the sorption capacity. The fixation of organic compounds on the surface of a solid sorbent is generally attributed to two coordination

Table 4. TOC distribution in liquid and solid phases after $2 \mathrm{~h}$ of test: initial concentration of catechol of $100 \mathrm{mg} \mathrm{L}^{-1}$, sorbent concentration of $5 \mathrm{~g} \mathrm{~L}^{-1}$ (sorption results of Figure 7).

\begin{tabular}{lccc}
\hline & \multicolumn{3}{c}{ Organic carbon distribution } \\
\cline { 2 - 4 } Sorbent & Liquid TOC (\%) & Solid TOC (\%) & Liquid + Solid TOC (\%) \\
\hline HAP_25 & $92.0 \pm 0.2$ & $8.5 \pm 0.5$ & $100.5 \pm 0.5$ \\
HAP_25_Zn & $78.4 \pm 1.4$ & $22.2 \pm 0.7$ & $100.6 \pm 1.6$ \\
HAP_80 & $99.5 \pm 0.8$ & $0.3 \pm 0.1$ & $99.8 \pm 0.8$ \\
\hline
\end{tabular}

modes. The first one calls for the formation of inner sphere complex, wherein organic ligand replaces water or hydroxyl groups of the liquid-solid interface to form metal-ligand bonds. The second one corresponds to the formation of the outer sphere complex, wherein organic ligand is fixed around the liquid-solid interface by hydrogen bonds [35,36]. In our case, the improvement of the sorption reactivity by zinc addition suggests that the formation of metal-ligand bonds must be favored, as illustrated in Figure 11. At the $\mathrm{pH}$ range of 7.5-8.5 as observed in our experiments (Figure 8), catechol exists mainly under the non-deprotonation $\left(\mathrm{C}_{6} \mathrm{H}_{4}(\mathrm{OH})_{2}\right)$ or semi-deprotonation $\left(\mathrm{C}_{6} \mathrm{H}_{4}(\mathrm{OH})\left(\mathrm{O}^{-}\right)\right)$ forms. At this $\mathrm{pH}$ range, the surface of the sorbents used in this work must be negatively charged, taking into account the value of $\mathrm{pH}_{\mathrm{ZPC}}$ in Table 2 . The nondeprotonation of catechol was more favorable with HAP_25_Zn than with HAP_25 or HAP_80, according to the $\mathrm{pH}$ evolution in Figure 8. This form of catechol has higher complexation with negative solid surface than the semi-deprotonation form which explains high reactivity of HAP_25_Zn. In addition, according to IUPAC Stability Constants Database, zinc has higher metal-ligand complexation constant with catechol than that of calcium, which allows also to explain the favorable effect of zinc addition on the fixation of this catechol.

These results help us to understand that, when HAPbased sorbent is used for the treatment of real wastewater containing simultaneously soluble metals and organic pollutants [19], it is possible that soluble metals are firstly fixed on the surface of the sorbent, followed by the fixation of organic compounds by ligand-metal complexation. Further characterizations need to be done with used sorbents to confirm this.

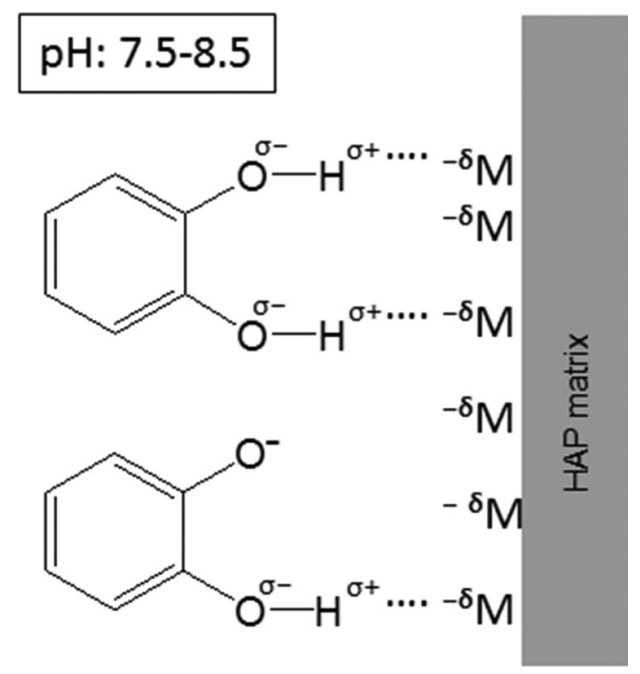

Figure 11. Illustration of catechol-metal bond; metal: Zn or Ca. 
From the results in Table 4, the sorption capacity of the sorbent could be calculated. The highest value was obtained with HAP_25_Zn, which reached $15 \mathrm{mg}$ of $\mathrm{C}$ per gram of sorbent. This result was very positive since activated carbon, which is specifically developed for the removal of organic compounds, was found to have the sorption capacity of $92 \mathrm{mg}$ of $\mathrm{C}$ per gram of sorbent [37].

\section{Conclusions}

HAP-based sorbents have been synthesized and investigated in the removal of catechol from an aqueous solution. Three sorbents have been evaluated: HAP_25 (synthesized at room temperature), HAP_80 (synthesized at $80^{\circ} \mathrm{C}$ ) and HAP_25_Zn (solid recovered after the fixation of $\mathrm{Zn}^{2+}$ by HAP_25). The most reactive sorbent was HAP_25_Zn, followed by HAP_25, then HAP_80. The $\mathrm{pH}$ of the sorption medium was found to be a crucial factor for the fixation of catechol. In the $\mathrm{pH}$ range observed for the sorption experiments, the surface of all the sorbents was negatively charged, which favored the complexation with the non-deprotonation $\left(\mathrm{C}_{6} \mathrm{H}_{4}(\mathrm{OH})_{2}\right)$ or semi-deprotonation $\left(\mathrm{C}_{6} \mathrm{H}_{4}(\mathrm{OH})\left(\mathrm{O}^{-}\right)\right)$forms of catechol. Soluble calcium $\left(\mathrm{Ca}^{2+}\right)$ and zinc $\left(\mathrm{Zn}^{2+}\right)$ contributed also to the degradation of catechol. In all cases, any mineralization was observed, as confirmed by the carbon balance analysis.

\section{Acknowledgements}

We gratefully acknowledge our industrial partner for the financial support. We also thank the colleagues at the RAPSODEE center, Mines Albi, for their technical help.

\section{Disclosure statement}

No potential conflict of interest was reported by the authors.

\section{References}

[1] Srivastava S, Agrawal SB, Mondal MK. A review on progress of heavy metal removal using adsorbents of microbial and plant origin. Environ Sci Poll Res. 2015;22:15386-15415.

[2] Ahmady-Asbchin S, Andres Y, Gerente C, et al. Natural seaweed waste as sorbent for heavy metal removal from solution. Environ Technol. 2009;30:755-762.

[3] Pham Minh D, Sebei H, Nzihou A, et al. Apatitic calcium phosphates: synthesis, characterization and reactivity in the removal of lead(II) from aqueous solution. Chem Eng J. 2012;198-199:180-190.

[4] Mobasherpour I, Salahi E, Pazouki M. Comparative of the removal of $\mathrm{Pb}^{2+}, \mathrm{Cd}^{2+}$ and $\mathrm{Ni}^{2+}$ by nano crystallite hydroxyapatite from aqueous solutions: adsorption isotherm study. Arab J Chem. 2012;5:439-446.

[5] Skwarek E. Natural seaweed waste as sorbent for heavy metal removal from solution. Environ Technol. 2009;30:755-762.

[6] Batton J, Kadaksham AJ, Nzihou A, et al. Trapping heavy metals by using calcium hydroxyapatite and dielectrophoresis. J Hazard Mater. 2007;139:461-466.

[7] Pham Minh D, Tran ND, Nzihou A, et al. Calcium phosphate based materials starting from calcium carbonate and orthophosphoric acid for the removal of lead(II) from an aqueous solution. Chem Eng J. 2014;243:280-288.

[8] Sebei H, Pham Minh D, Nzihou A, et al. Sorption behavior of $\mathrm{Zn}$ (II) ions on synthetic apatitic calciumphosphates. Appl Surf Sci. 2015;357:1958-1966.

[9] Alzaydien AS, Manasreh W. Equilibrium, kinetic and thermodynamic studies on the adsorption of phenol onto activated phosphate rock. Int J Phys Sci. 2009;4:172-181.

[10] Bahdod A, El Asri S, Saoiabi A, et al. Adsorption of phenol from an aqueous solution by selected apatite adsorbents: kinetic process and impact of the surface properties. Water Res. 2009;43:313-318.

[11] Bouyarmane $H$, El Asri S, Rami A, et al. Pyridine and phenol removal using natural and synthetic apatites as low cost sorbents: influence of porosity and surface interactions. J Hazard Mater. 2010;181:736-741.

[12] Lin K, Pan J, Chen Y, et al. Study the adsorption of phenol from aqueous solution on hydroxyapatite nanopowders. J Hazard Mater. 2009;161:231-240.

[13] Bengtsson A. Solubility and surface complexation of apatites, PhD report. Umeå, Sweden: Umeå University; 2007.

[14] Vega ED, Colinas PA. Adsorption of fumaric and maleic acids onto hydroxyapatite: a thermodynamic study. J Argentine Chem Soc. 2009;97:195-206.

[15] Wei W, Zhang X, Cui J, et al. Interaction between low molecular weight organic acids and hydroxyapatite with different degrees of crystallinity. Colloid Surf A Phys Eng Aspects. 2011;392:67-75.

[16] Mahmud K, Islam MA, Mitsionis A, et al. Adsorption of direct yellow 27 from water by poorly crystalline hydroxyapatite prepared via precipitation method. Desalin Water Treat. 2012;41:170-178.

[17] Chirdon WM, O'Brien WJ, Robertson RE. Adsorption of catechol and comparative solutes on hydroxyapatite. J Biomed Mater Res. 2003;66B:532-538.

[18] Pham Minh D, Gallezot P, Azabou S, et al. Catalytic wet air oxidation of olive oil mill effluents: 4 . treatment and detoxification of real effluents. Appl Catal B Env. 2008;84:749-757.

[19] Lyczko N, Nzihou A, Sharrock P. Calcium phosphate sorbent for environmental application. Proc Eng. 2014;83:423-431.

[20] Faria PCC, Orfao JJM, Pereira MFR. Adsorption of anionic and cationic dyes on activated carbons with different surface chemistries. Water Res. 2004;38:2043-2052.

[21] Smiciklas ID, Milonjic SK, Pfendt P, et al. The point of zero charge and sorption of cadmium (ii) and strontium (II) ions on synthetic hydroxyapatite. Sep Purif Technol. 2000;18:185-194.

[22] Pham Minh D, Lyczko $N$, Sebei $H$, et al. Synthesis of calcium hydroxyapatite from calcium carbonate and 
different orthophosphate sources: a comparative study. Mater Sci Eng. B. 2012;177:1080-1089.

[23] Rootare HM, Craig RG. Vapor phase adsorption of water on hydroxyapatite. J Dental Res. 1977;56:1437-1448.

[24] Herschke L. Polymer controlled mineralization of zinc phosphate hydrates and applications in corrosion protection, catalysis and biomedicine [Ph.D. thesis report]. Johannes-Gutenberg-Universität Mainz; 2004.

[25] Pham Minh D, Tran ND, Nzihou A, et al. Novel one-step synthesis and characterization of bone-like carbonated apatite from calcium carbonate, calcium hydroxide and orthophosphoric acid as economical starting materials. Mater Res Bull. 2014;51:236-243.

[26] Pham Minh D, Nzihou A, Sharrock P. Carbonated hydroxyapatite starting from calcite and different orthophosphates under moderate hydrothermal conditions: synthesis and surface reactivity in simulated body fluid. Mater Res Bull. 2014;60:292-299.

[27] Fowler BO. Infrared studies of apatites. I. vibrational assignements for calcium, strontium, and barium hydroxyapatites utilizing isotopic substitution. J Inorg Chem. 1974;13:194-207.

[28] Elliot JC. Structure and chemistry of the apatites and other calcium orthophosphates. Amsterdam: Elsevier; 1994.

[29] Fleet ME, Li X. Local structure of channel ions in carbonate apatite. Biomaterials. 2005;26:7548-7554.
[30] Lebedev AV, Ivanova MV, Timoshin AA, et al. Effect of group ii metal cations on catecholate oxidation. Chemphyschem. 2007;8:1863-1869.

[31] Feenstra TP, de Bruyn PL. Light scattering studies on solutions containing calcium phosphates. J Colloid Inter Sci. 1980;73:431-437.

[32] Luck F. Wet air oxidation: past, present and future. Catal Today. 1999;53:81-91.

[33] Zapico RR, Marin P, Diez FV, et al. Influence of operation conditions on the copper-catalysed homogeneous wet oxidation of phenol: development of a kinetic model. Chem Eng J. 2015;270:122-132.

[34] Bhatt RR, Shah BA. Sorption studies of heavy metal ions by salicylic acid-formaldehyde-catechol terpolymeric resin: isotherm, kinetic and thermodynamics. Arabian J Chem. 2015;8:414-426.

[35] McBride MB, Wesselink LG. Chemisorption of catechol on gibbsite, boehmite, and noncrystalline alumina surfaces. Environ Sci Technol. 1988;22:703-708.

[36] Nordin J, Persson P, Laiti E, et al. Adsorption of o-phthalate at the water-boehmite $(\mathrm{\gamma}-\mathrm{AlOOH})$ interface: evidence for two coordination modes. Langmuir. 1997;13:40854093.

[37] Kumar A, Kumar S, Kumar S. Adsorption of resorcinol and catechol on granular activated carbon: equilibrium and kinetics. Carbon. 2003;41:3015-3025. 